\title{
Smoke on the Water: Comparative Assessment of Combined Thermal Shock Treatments for Control of Invasive Asian Clam, Corbicula fluminea
}

\author{
Neil E. Coughlan $\mathbb{1}^{1,2,3} \cdot$ Ross N. Cuthbert ${ }^{4,2} \cdot$ Eoghan M. Cunningham ${ }^{1,2} \cdot$ Stephen Potts $^{2} \cdot$ Diarmuid McSweeney $^{2} \cdot$ \\ Gina Y. W. Vong $^{2} \cdot$ Emma Healey $^{1,2} \cdot$ Kate Crane $^{1,2} \cdot$ Joe M. Caffrey $^{5}$. Frances E. Lucy ${ }^{6}$ Eithne Davis ${ }^{6}$. \\ Jaimie T. A. Dick ${ }^{1,2}$
}

Received: 7 December 2020 / Accepted: 12 April 2021 / Published online: 29 April 2021

(c) The Author(s) 2021

\begin{abstract}
Suppression of established populations of invasive alien species can be a complex and expensive process, which is frequently unsuccessful. The Asian clam, Corbicula fluminea (Müller, 1774), is considered a high impact invader that can adversely alter freshwater ecosystems and decrease their socioeconomic value. To date, $C$. fluminea continues to spread and persist within freshwater environments worldwide, despite repeated management attempts to prevent dispersal and suppress established populations. As extensive $C$. fluminea beds can often become exposed during low-water conditions, the direct application of hot or cold thermal shock treatments has been proposed as suitable mechanism for their control. Further, mechanical substrate disturbance may enhance the efficacy of thermal shock treatments by facilitating exposures to multiple layers of buried clams. In the present study, we advanced these methods by assessing combined applications of both hot and cold thermal shock treatments for control of $C$. fluminea, using steam spray $\left(\geq 100^{\circ} \mathrm{C} ; 350 \mathrm{kPa}\right)$, low- or high-intensity open-flame burns $\left(\sim 1000{ }^{\circ} \mathrm{C}\right)$ and dry ice $\left(-78^{\circ} \mathrm{C}\right)$. In a direct comparison of raking combined with hot thermal shock applications, both steam and high-intensity openflame treatments tended to be most effective, especially following multiple applications. In addition, when hot thermal treatments are followed by a final cold shock (i.e. dry ice), steam treatments tended to be most effective. Further, when dry ice was applied either alone or prior to an application of a hot shock treatment, substantial if not complete $C$. fluminea mortality was observed. Overall, this study demonstrated that combined applications of hot and cold thermal shock treatments, applied following the disruption of the substrate, can substantially increase $C$. fluminea mortality compared to separate hot or cold treatments.
\end{abstract}

Keywords Invasive alien species $\cdot$ Biosecurity $\cdot$ Open-flame heat torch $\cdot$ Thermal shock $\cdot$ Population control $\cdot$ Eradication

Neil E. Coughlan

ncoughlan02@qub.ac.uk

1 Institute for Global Food Security, School of Biological Sciences, Queen's University Belfast, 19 Chlorine Gardens, Belfast BT9 5DL Northern Ireland, UK

2 Queen's Marine Laboratory, Queen's University Belfast, 12-13 The Strand, Portaferry BT22 1PF Northern Ireland, UK

3 School of Biological, Earth and Environmental Sciences, University College Cork, Distillery Fields, North Mall, Cork, Ireland

4 GEOMAR, Helmholtz-Zentrum für Ozeanforschung Kiel, Düsternbrooker Weg 20, 24105 Kiel, Germany

5 INVAS Biosecurity Ltd., 82 Lakelands Close, Stillorgan, County Dublin, Ireland

6 Centre for Environmental Research, Innovation \& Sustainability, Institute of Technology Sligo, Ash Lane, County Sligo, Ireland

\section{Introduction}

Invasive alien species are considered a key component of global change, as established invader populations can detrimentally alter ecological and evolutionary dynamics, which in turn can negatively impact ecosystems and decrease their socioeconomic value (Sousa et al. 2009; 2014; Crane et al. 2020). In general, management options for suppression and eradication can be complex undertakings, which are often costly and resource intensive to preform (Caffrey et al. 2011b; Wittmann et al. 2012a, b; Piria et al. 2017). Further, the efficacy of many control techniques are unknown, inadequate and damaging to nontarget species (Wittmann et al. 2012a, b; Caffrey et al. 2014; Sousa et al. 2014). Accordingly, there is a clear and urgent need to develop appropriate and readily available control 
methods, which maximise efficacy of treatment towards target species, but minimise broad-scale environmental damage (Coughlan et al. 2018a, b; Cuthbert et al. 2018; 2019). Ideally, any such method should be simple and relatively straightforward to apply within field scenarios (Coughlan et al. 2018b). This is especially important as the implementation of control strategies can be impeded by numerous obstacles, including lack of public awareness and engagement (Davis et al. 2018), poor enforcement of regulations, inadequate monitoring and rapid-response protocols (Caffrey et al. 2014) and legal barriers, such as accessibility of private property (Piria et al. 2017). In addition, more traditional methods of invader control, such as chemical treatments, are no longer available due to legislative changes in light of undesirable environmental or human-health effects or are simply inappropriate or ineffective for large, open waterbodies rather than industrial settings (Sousa et al. 2014).

The Asian clam, Corbicula fluminea (Müller, 1774), is a high impact invasive bivalve, which is considered a major threat to the function and biodiversity of freshwater ecosystems worldwide (Sousa et al. 2008; 2014). As a dominant filter feeder, $C$. fluminea can homogenise macroinvertebrate communities, physically alter benthic habitats and disrupt ecosystem-regulating services (McMahon 1982; Sousa et al. 2008; 2014). Equally, its presence can have substantial negative economic impacts, through macrofouling of agricultural, municipal and raw water extraction systems, increased sedimentation rates and the closure of sport fisheries and amenity areas (Nakano and Strayer 2014; Sousa et al. 2014). Moreover, C. fluminea has shown a high degree of physiological and ecological plasticity (Sousa et al. 2014), and an exceptional capacity for human-mediated or even zoochorous dispersal (Belz et al. 2012; Coughlan et al. 2017b). Despite repeated management efforts to curtail invader spread, $C$. fluminea continues to spread across hydrologically unconnected freshwater systems (Barbour et al. 2013; Caffrey et al. 2016; Colwell et al. 2017). Further, at the current predicted rate of climate change, novel river basins will be increasingly at risk of invasion as new areas of suitable habitat become available, especially at higher latitudes (Gama et al. 2017).

Once established, C. fluminea can form dense and expansive populations that are notoriously difficult to eradicate or control (Caffrey et al. 2011a; Wittmann et al. 2012a, b). For example, although extensive eradication and control experiments can achieve a short term reduction of both $C$. fluminea density and biomass, none have successfully provided a substantial long-term management solution for C. fluminea populations (Wittmann et al. 2012a, b; Sheehan et al. 2014). Accordingly, there is an urgent need to develop, refine and validate tools capable of providing rapid yet long-term control and eradication of emerging and existing C. fluminea populations (Colwell et al. 2017; Coughlan et al. 2018b; 2019b; 2020).

Recently, through a series of laboratory experiments, Coughlan et al. (2018b) observed that cold thermal shock treatments, caused by an application of dry ice pellets (i.e. solid $\mathrm{CO}_{2}$ pellets at $-78^{\circ} \mathrm{C}$ ), could be used to kill tidally exposed, substrate-residing $C$. fluminea. Similarly, Coughlan et al. (2019b) demonstrated that open-flame torch ( $\sim 1000^{\circ} \mathrm{C}$, i.e. hot thermal treatments) can also be used to kill mud-dwelling $C$. fluminea. Building on this, Coughlan et al. (2020) showed that a continuous jet of steam $\left(\geq 100^{\circ} \mathrm{C}\right)$ can likewise be used as an effective tool for substantial population control of low-water exposed bivalves. Overall, when taken together, these studies show the usefulness of individual thermal shock treatments as methods for effective, rapid-response control and possible eradication of $C$. fluminea populations (Coughlan et al. 2020). In particular, thermal shock treatments potentially represent a straightforward, user and environmentally friendly mechanism for causing substantial if not complete mortality of invasive alien bivalve species residing upon and within exposed lake, river or canal beds (Crane et al. 2019; Joyce et al. 2019; Coughlan et al. 2020). Notably, Coughlan et al. (2019b) observed an increased efficacy for thermal shock treatments when applied following the mechanical disruption of the structural integrity of the substrate, whereby the substrate was raked and churned to expose buried $C$. fluminea. Following the work of Coughlan et al. (2019b; 2020), we suggest that combined approaches require investigation, whereby multiple applications of various control mechanisms could be combined and strategically applied to increase overall bivalve mortality. Further, dry ice applications may increase mortality if the penetration of a cold thermal shock is greater than hot thermal applications, through freezing of the substrate surrounding $C$. fluminea. In particular, a sudden change of temperature that prevents any chance of acclimation, especially over large temperature gradients, will likely increase mortality rates due to escalated thermal shock (e.g. McMahon and Ussery 1995). As such, combined applications of dry ice and hot thermal treatments may increase overall mortality, with potential to reduce time and labour costs by decreasing the frequency and duration of hot thermal exposure periods. Accordingly, the application of a cold or hot thermal shock treatment immediately following the application of a contrasting hot or cold treatment will likely be more destructive. Further, such alternation of hot and cold thermal treatments could reduce the intensity and/ or duration of treatment needed to kill substrate dwelling specimens of $C$. fluminea.

First, using simulated bivalve beds, we ascertained the effectiveness of both reduced intensity and exposure time without the addition of a cold thermal shock (i.e. dry ice). 
To achieve this, we comparatively assessed the combined effects of substrate disruption, i.e. raking, paired with various rapidly applied hot thermal shock treatments, which consisted of steam, low- or high-intensity open-flame burns without the addition of a cold thermal shock. The effects of raking combined with hot thermal shock treatments, followed by a final application of cold thermal shock that was delivered via the application of dry ice, was also examined. Similarly, the inverse of the process was likewise assessed, whereby following substrate raking, a cold thermal shock treatment was immediately applied, followed by the application of a hot thermal shock. A temperature gradient of cold to hot is particularly interesting as many bivalve species show greater tolerance for sudden decline rather than a rapid increase in temperatures (e.g. presence of haemolymph ice-nucleating proteins; Madison et al. 1991). Therefore, a sudden upwards elevation of temperature is expected to be more damaging than accelerated cooling, particularly at a sub-lethal cellular level (e.g. Hicks and McMahon 2002). Overall, we hypothesised that exposure to the more extreme heat delivery of an intense open-flame burn would result in greater $C$. fluminea mortality than steam or low-intensity burns. Similarly, it was expected that the effect of combined hot and cold thermal shock treatments would increase overall bivalve mortality rates. Thus, we hypothesised that cold followed by hot thermal shock applications would cause even greater $C$. fluminea mortality than application of hot followed by cold shock treatments, given that a warmed substrate could inhibit its penetration by extreme cold. Thus, through a series of factorial experiments, we assessed potential avenues for the further development of thermal shock treatments as a means of rapid-response invader control.

\section{Methods}

\section{Specimen Collection and Maintenance}

Specimens of $C$. fluminea were collected from the extensive, tidally exposed area at Poulmounty on the River Barrow in the Republic of Ireland $\left(52^{\circ} 29^{\prime} 15.11^{\prime \prime} \mathrm{N}, 6^{\circ} 55^{\prime}\right.$ $42.20^{\prime \prime} \mathrm{W}$ ) during May 2019, and transported in source water to Queen's University Marine Laboratory, Northern Ireland. In the laboratory, specimens were kept within a controlled temperature (CT) room at $13{ }^{\circ} \mathrm{C}$, on a $12: 12 \mathrm{~h}$ light-to-dark schedule. All specimens were maintained in aerated aquaria using locally sourced lake water (Lough Cowey: $\left.54^{\circ} 24^{\prime} 41.79^{\prime \prime} \mathrm{N}, 5^{\circ} 32^{\prime} 25.96^{\prime \prime} \mathrm{W}\right)$. Specimens were allowed to acclimatise to these conditions for at least 1 week prior to experimentation. Further, only living and feeding specimens were selected for experimental work, i.e. selected specimens that were observed opening to feed, and reclosed when disturbed. Adult $C$. fluminea specimens were selected by shell height $(\mathrm{SH})$, i.e. from the highest point on the umbo to the ventral margin of the shell 'umbo to gape'.

\section{Experiment 1: Effect of Raking with Hot Thermal Shock Treatments}

To mimic field scenarios, whereby $C$. fluminea are found residing in low-water exposed substrate, specimens ( $\mathrm{SH}$ min.-max.: 18-20 mm) were encapsulated within damp sand patches. Groups of 30 C. fluminea were randomly mixed into a damp sand layer to create each simulated patch, which is representative of a realistic $C$. fluminea bed structure $\left(25 \mathrm{~cm} \times 25 \mathrm{~cm} ; \sim 4 \mathrm{~cm}\right.$ deep: 480 ind. $\left.\mathrm{m}^{-2}\right)$. Combined applications of rake and thermal shock treatments were then examined, further building on the results of Coughlan et al. (2019b; 2020), who identified that joint rake and thermal shock treatments can kill substrate-residing $C$. fluminea. In particular, much of the experimental set-up deployed by Coughlan et al. (2020) was also used by the present study to enable comparison between these works. The initial raking phase was used to churn-up and furrow the substrate, to expose greater numbers of $C$. fluminea to the subsequent thermal shock treatments. Specimens were exposed to a continuous jet of steam $\left(\geq 100{ }^{\circ} \mathrm{C} ; 350 \mathrm{kPa}\right.$; Karcher ${ }^{\oplus}$ S3 Steam Cleaner), a low-intensity open-flame burn $\left(\sim 1000^{\circ} \mathrm{C}\right.$; ASAB weed-burner AS-09463: butane gas) or high-intensity open-flame burn $\left(\sim 1000^{\circ} \mathrm{C}, 400 \mathrm{kPa}\right.$ : Rothenberger, Romaxi Power Burner: butane gas) for a 2.5min period, following a 30-s period of patch raking (Fiskars soil rake). A thermal exposure duration lasting $2.5 \mathrm{~min}$ was selected as 2- and 3-min exposure periods have previously been observed to deliver high but not complete mortality of C. fluminea (Coughlan et al. 2020). The low-intensity torch had a shorter 'blue-flame' length than the high-intensity device, i.e. a shorter hottest burning section of flame, at $\sim 5$ and $\sim 36 \mathrm{~cm}$, respectively. The combined applications of rake and thermal shock were examined for single, double or triple treatments ( $n=3$ per experimental group). Treatments conducted in the absence of raking were not considered for Experiment 1, as results from this approach have already been adequately demonstrated in Coughlan et al. (2019b; 2020). Control groups were likewise formed into sand patches, which were each raked for up to three consecutive 30 -s periods and allowed to air dry for a 2.5 -min period following each raking event. Control patches were not exposed to thermal shock treatments. Following a 15-min cooling period, initiated after the final thermal shock treatment had occurred, specimens were immediately extracted from the patch and returned to the CT room. Replicates were then placed individually within $600 \mathrm{ml}$ of dechlorinated tap water taken from a continuously aerated source $\left(11-13{ }^{\circ} \mathrm{C}\right.$ ) for a $24-\mathrm{h}$ recovery period, after which mortality 
was assessed. Specimens were considered dead if they were gaping, or failed to respond to a tactile stimulus, or did not reclose (see Matthews and McMahon 1999).

\section{Experiment 2: Effect of Raking with Hot Thermal Shock Treatments, then a Final Cold Shock Application}

To assess the combined efficacy of combined hot and cold thermal shock treatments to kill sand dwelling $C$. fluminea, specimens were factorially exposed to treatments under both non-disrupted substrate and disrupted substrate (i.e. non-raked or raked). This was immediately followed by the application of a hot thermal shock, followed by a single final cold thermal shock. Hot thermal shock treatments consisted of steam spray, a low-intensity open-flame burn or high-intensity open-flame burn (see above). Cold thermal shock was delivered using $9 \mathrm{~mm}$ dry ice pellets, (i.e. solid $\mathrm{CO}_{2}$ pellets at $-78{ }^{\circ} \mathrm{C}$ ). As described above, groups of 30 C. fluminea specimens (SH min.-max.: 19-21 mm) were mixed into damp sand patches. Following an initial 30-s non-raking or raking period, specimens were exposed to steam or burn treatments for a 2.5 -min period. For raketreated groups, all combinations of experimental applications were examined for single, double or triple treatments $(n=3$ per experimental group). Immediately following the application of the final hot thermal shock treatment, $800 \mathrm{~g}$ of dry ice was evenly applied to the upward facing surface area of the patch, for a 30-min period. Following this, all specimens were extracted from the patch. If required, specimens were carefully separated from dry ice by hand, using a small metal ice pick and cool dechlorinated tap water $\left(\sim 6^{\circ} \mathrm{C}\right)$. Control patches were raked for up to three 30 -s periods (i.e. for the four rake treatment groups) and allowed to air dry for a 2.5 -min period following each raking event. In addition, control patches were also allowed to air dry for a 30-min period following the last raking, or non-raking, event. Control patches were not exposed to any thermal treatments, hot or cold. As before, all specimens were returned to the CT room and left to recover for $24 \mathrm{~h}$, after which mortality was assessed.

\section{Experiment 3: Effect of Raking with Cold Thermal Shock Treatments, then a Final Hot Shock Application}

To investigate the combined impact of cold followed by hot thermal shock treatments on sand encapsulated $C$. fluminea, specimens were exposed to combined applications of nondisrupted and disrupted substrate, dry ice and various hot thermal shock treatments in a fully factorial experiment. As above, the integrity of the substrate was disrupted through raking, while cold thermal shock was achieved with the application of $9 \mathrm{~mm}$ dry ice pellets. Hot thermal shock treatments consisted of steam spray or high-intensity openflame burns. Once again, groups of $30 \mathrm{C}$. fluminea specimens (SH min.-max.: 20-22 mm) were mixed into damp sand patches. Raking periods lasted for $30 \mathrm{~s}$, and were followed by the application of $800 \mathrm{~g}$ of dry ice. Dry ice was then evenly spread over the entire patch, with exposure lasting for a 30-min period. Following this, each patch received either no further treatment or a hot thermal shock lasting $2.5 \mathrm{~min}$. All combinations of experimental applications were examined for single, double or triple treatments ( $n=3$ per experimental group). Once the final hot thermal shock was complete, specimens were allowed to cool for a 15-min period before being extracted from the patch. Control patches were raked for up to three 30 -s periods and allowed to air dry for a 2.5-min period following each raking event. Control patches were also allowed to air dry for a 15-min period following the last raking event. Control patches were not exposed to any thermal treatments, hot or cold. As above, all specimens were returned to the CT room and left to recover for $24 \mathrm{~h}$ after which mortality was assessed. Low-intensity burns were omitted due to a lack of appropriately standardised $C$. fluminea specimens, as well as via an indication that frozen substrate can effectively insulate clams at the low-intensity burns, gleaned from a pre-experimental scoping exercise.

\section{Data Analyses}

Bivalve mortality rates in each experiment were analysed separately according to thermal shock and rake treatments and their interaction, using binomial generalised linear models. Bias reductions were employed for Experiment 3, owing to complete separation of residuals (Firth 1993; Kosmidis 2014). Analysis of deviance with type III sums of squared was used to calculate effect sizes and $P$ values (Fox and Weisberg 2011). Tukey tests via estimated marginal means were used to undertake post-hoc pairwise comparisons (Lenth 2018). All analyses were undertaken using the $\mathrm{R}$ statistical software environment ( $\mathrm{R}$ Core Development Team 2018).

\section{Results}

\section{Experiment 1: Effect of Raking with Hot Thermal Shock Treatments}

Whilst control mortality never exceeded $7 \%$ across all rake treatments, up to $100 \%$ C. fluminea mortality was observed following triple rake and thermal shock applications via high-intensity open-flame burn treatments (Fig. 1). Thermal shock and rake treatments interacted significantly 


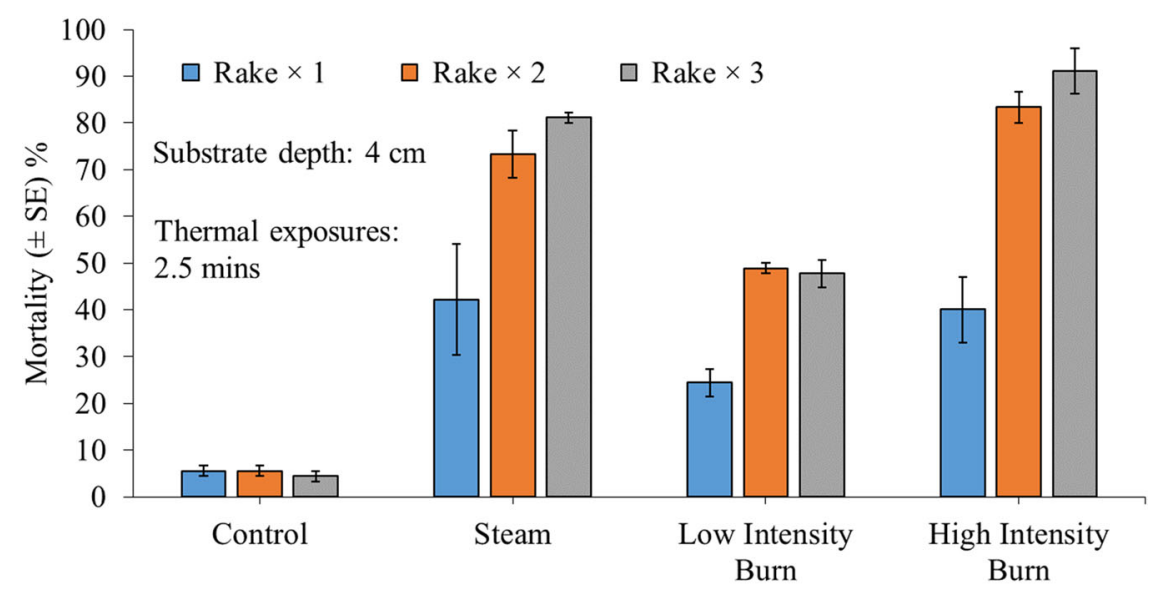

Treatment

Fig. 1 Mean mortality $( \pm \mathrm{SE})$ of 30 adult Corbicula fluminea specimens (480 ind. $\mathrm{m}^{-2}$ ) $24 \mathrm{~h}$ following exposure to the application of combined 30-s rake and 2.5-min thermal shock treatments, while residing within a $4 \mathrm{~cm}$ deep patch of damp sand substrate. Thermal treatments consisted of steam spray $\left(\geq 100^{\circ} \mathrm{C}\right)$, low-intensity or high-

$\left(\chi^{2}=19.13, \quad \mathrm{df}=6, \quad P=0.004\right)$. Whilst a significant increase in mortality was always induced via hot thermal shock compared to controls (all $P<0.01$ ), there was no significant difference among thermal shock treatments following single rake applications (all $P>0.05$ ). Contrastingly, after double and triple rake applications, differences emerged among heat treatments. Mortality rates were significantly higher following steam or high-intensity openflame treatments relative to low-intensity burning after multiple raking treatments (all $P<0.01$ ). Although highintensity open-flame treatments tended to be most effective overall, both steam and high-intensity open-flame always caused similar levels of $C$. fluminea mortality rates (all $P>$ $0.05)$.

\section{Experiment 2: Effect of Raking with Hot Thermal Shock Treatments, then a Final Cold Shock Application}

Whilst control mortality never exceeded $10 \%$, triple steam and open-flame thermal shock treatments, followed by a final dry ice exposure, caused up to $100 \%$ mortality of sand dwelling C. fluminea (90-100\%: Fig. 2). Within combined hot and cold thermal shock application, steam exposures tended to be the most efficacious thermal treatment overall. As before, there was a significant interaction between thermal shock and rake treatments $\left(\chi^{2}=62.94\right.$, df $=9, P<$ $0.001)$. Control mortality was always significantly lower than thermal shock treated groups, irrespective of raking exposure (all $P<0.05$ ). In the absence of raking, combined steam and dry ice treatments were significantly more effective in inducing mortality than low- or high-intensity intensity open-flame exposure $\left(\sim 1000^{\circ} \mathrm{C}\right)$. Although raked for up to three times, control patches were not exposed to thermal treatment. All treatments were performed as a single, double $(\times 2)$ or triple $(\times 3)$ applications ( $n=3$ per experimental group)

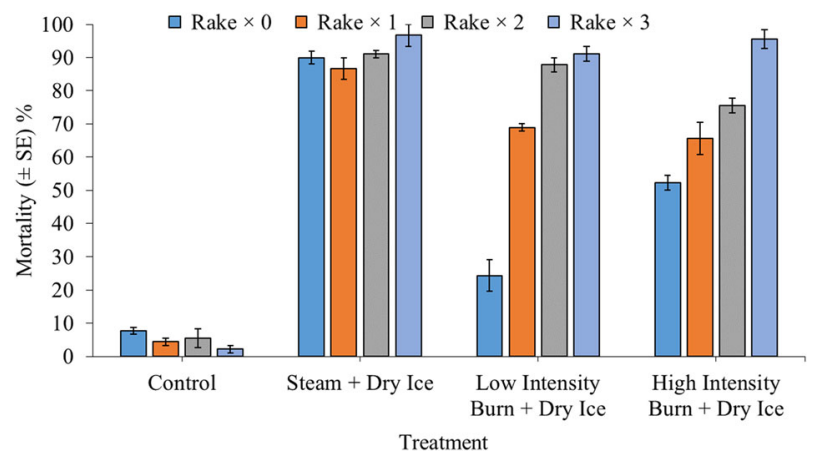

Fig. 2 Mean mortality $( \pm$ SE) of 30 adult Corbicula fluminea specimens (480 ind $\mathrm{m}^{-2}$ ) $24 \mathrm{~h}$ following exposure to the application of combined 30-s rake and 2.5-min thermal shock treatments, while residing within a $4 \mathrm{~cm}$ deep patch of damp sand substrate. Thermal treatments consisted of steam spray $\left(\geq 100^{\circ} \mathrm{C}\right)$, low-intensity or highintensity open-flame exposure $\left(\sim 1000^{\circ} \mathrm{C}\right)$. Patches were evenly covered with $800 \mathrm{~g}$ of dry ice for a 30-min period immediately after the final hot thermal shock application. Control patches were not exposed to thermal treatment, hot or cold, but were raked for up to three times. Treatments were performed either in the absence of raking, or with single, double $(\times 2)$ or triple $(\times 3)$ applications $(n=3$ per experimental group)

open-flame equivalents (both $P<0.001$ ). In turn, highintensity burning followed by dry ice was more efficacious than low-intensity open-flame equivalents $(P=0.001)$. However, following single, double or triple rake treatments, differences among low- and high-intensity open-flame treatments, followed by dry ice, were not statistically clear (all $P>0.05$ ). Hot thermal shock treatments with steam were significantly more effective than both the open-flame treatments for single rake exposures (both $P<0.05$ ). However, although steam treatments were more effective than 


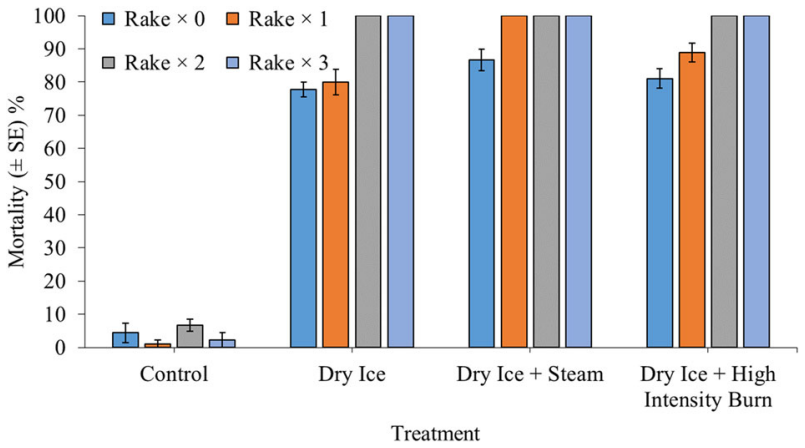

Fig. 3 Mean mortality $( \pm$ SE) of 30 adult Corbicula fluminea specimens (480 ind $\mathrm{m}^{-2}$ ) $24 \mathrm{~h}$ following exposure to the application of combined 30-s rake and 2.5-min thermal shock treatments, while residing within a $4 \mathrm{~cm}$ deep patch of damp sand substrate. Patches were evenly covered with $800 \mathrm{~g}$ of dry ice for a 30 -min period prior to the application of each hot thermal shock treatment, which consisted of steam spray $\left(\geq 100^{\circ} \mathrm{C}\right)$, low-intensity or high-intensity open-flame exposure $\left(\sim 1000^{\circ} \mathrm{C}\right)$. Although raked for up to three times, control patches were not exposed to thermal treatment, hot or cold. Treatments were performed either in the absence of raking, or with single, double $(\times 2)$ or triple $(\times 3)$ applications $(n=3$ per experimental group)

high-intensity burns $(P=0.03)$, they were not more effective than low-intensity burns $(P=0.89)$ under double rake exposures. Conversely, there were no significant differences among thermal shock treatments following triple raking (all $P>0.05)$. Therefore, differences among combined hot and cold thermal shocks were driven by rake treatments, with raking especially enhancing the efficacy of open-flame treatment groups.

\section{Experiment 3: Effect of Raking with Cold Thermal Shock Treatments, then a Final Hot Shock Application}

Although exposed to three rake cycles, control specimen mortality never exceeded $10 \%$. However, cold thermal shock via dry ice consistently caused $100 \%$ mortality of $C$. fluminea following double and triple applications, irrespective of additional hot thermal shock treatments (Fig. 3). In addition, cold thermal shock treatments followed by a steam application consistently killed all sand dwelling C. fluminea, even following just single rake applications. Thermal shock and rake effects, again, interacted significantly in causing $C$. fluminea mortality $\left(\chi^{2}=32.85\right.$, df $=9, P<0.001)$. Cold thermal shock with or without hot thermal shock always caused significant mortality relative to controls, irrespective of rake treatment (all $P<0.001$ ). Nevertheless, thermal shock treatments were always statistically similar following non-raked, double rake and triple rake applications (all $P>0.05$ ). Contrastingly, following single rake treatments, the addition of steam significantly increased $C$. fluminea mortality compared to dry ice alone $(P=0.04)$. Overall, although dry ice was highly efficacious in causing mortality of $C$. fluminea alone, hot thermal shock applications bolstered cold thermal shock impacts under instances with reduced substrate disturbance.

\section{Discussion}

Previous studies have shown that thermal shock treatments caused by dry ice (Coughlan et al. 2018b), steam spray (Coughlan et al. 2019a; Joyce et al. 2019) and open-flame burn applications (Coughlan et al. 2019b; 2020) can be used to rapidly kill substrate-residing $C$. fluminea under laboratory conditions. The present study has confirmed and significantly progressed these observations through a comparative assessment, for applications of substrate disruption (i.e. raking) followed by various combined hot and cold thermal shock treatments. Initially, Experiment 1 highlighted that high-intensity burns are more efficacious than low-intensity burning, especially following multiple applications, in advance of the combined application of hot and cold thermal treatments in Experiments 2 and 3 . Interestingly, steam spray treatments were also highly effective. Further, Experiment 2 revealed that the application of hot and cold (i.e. dry ice) thermal shock treatments can substantially increase $C$. fluminea mortality. Once again, steam and high-intensity open-flame burns were generally observed to cause greater mortality than lowintensity burns. In particular, the efficacy of raking and multiple thermal shock applications was clearly evidenced, and particularly for open-flame treatments. Building on this, Experiment 3 demonstrated that the application of dry ice, especially when combined with substrate raking over multiple treatments, can effectively kill sand dwelling $C$. $f l u$ minea. Comparatively, Experiments 2 and 3 show that when cold thermal shock treatments are followed by the application of a hot thermal shock, a greater proportion of $C$. fluminea can be killed with a single exposure, with $100 \%$ mortality being achievable with two or fewer applications of combined rake and thermal shock treatments.

As previously described by Coughlan et al. (2020), groups of both surface-dwelling and buried $C$. fluminea can be completely killed, following 1- or 5-min steam exposures, respectively, (as per Figure 2 in Coughlan et al. op. cit.). Similarly, open-flame heat torch treatments can be used for effective and substantial control of $C$. fluminea populations, especially when combined with the prior disruption of substrate integrity to bring more specimens towards the surface (Figure 5 in Coughlan et al. 2019b; Figure 4 in Coughlan et al. 2020). Although not statistically clear, Coughlan et al. (2020) observed that high-intensity open-flame burn treatments tended to kill marginally more C. fluminea than steam applications (Figure 4 in Coughlan et al. op. cit.), and this is thought to be most likely due to the 
more intense heat generated by open-flame relative to steam, i.e. $\sim 1000$ and $\sim 100{ }^{\circ} \mathrm{C}$, respectively. In the present study, which sought to ascertain the effects of combined hot and cold thermal shock treatments over a wider temperature gradient, steam appears to have an equal and sometimes greater efficacy than high-intensity open-flame burns when combined with an application of dry ice. A similar trend was observed in Fig. 4 in Coughlan et al. (2020). As steam tends to condense onto substrate as hot water, this heated water may penetrate through the patch to warm and further saturate encapsulated $C$. fluminea. Subsequent addition of dry ice will then rapidly cool and freeze the substrate causing thermal shock (see Coughlan et al. 2018b), through a sudden change over a wide temperature range. Indeed, in Experiment 2, it was difficult to extract $C$. fluminea from patches following a final treatment of dry ice as the substrate froze around the specimens. Similarly, the application of steam condensing into hot water, following an initial dry ice treatment, likewise causes a sudden temperature change within experimental patches. In contrast, substrate appears to insulate buried $C$. fluminea from open-flame treatments, which tends to dry and solidify the sand substrate (see Coughlan et al. 2020).

Overall, we suggest that applications of raking combined with both cold and hot thermal shock treatments could be used as a rapid-response tool to control emerging and established populations of $C$. fluminea found residing at dewatered locations, such as exposed river, lake and canal beds. In particular, it appears that cold thermal shock treatments followed by hot thermal applications of steam or high-intensity open-flame burn would likely be the most effective approach. In the absence of substrate disturbance measures, steam followed by dry ice appears to be the most efficacious means of control. However, further validation and clarification of these techniques is required. For example, the impact of deeper substrate depths will likely reduce the efficacy of thermal shock treatments (Coughlan et al. 2020), and this will need to be considered in greater detail. Further, although completely water-saturated sand substrate can reduce the efficacy of rake and steam treatments (Coughlan et al. 2020), the application of dry ice to cause a freezing effect may further increase mortality rates in such scenarios. However, even though dry ice-induced cold thermal shock treatments have been shown to effectively kill $C$. fluminea at a submerged water depth of up to $10 \mathrm{~cm}$ (Coughlan et al. 2018b), this has not yet been examined under field conditions. Hitherto, field-tested underwater mechanical control methods for bivalve populations, such as benthic barriers and dredging, have proven problematic, costly and unreliable (see, e.g. Wittmann et al. 2012a, b; Sheehan et al. 2014). However, as argued by Coughlan et al. (2020), thermal shock treatments could be combined with mechanical dredging methods to improve bivalve population management strategies. In turn, such treatments may enhance waste disposal practices, effectively ensuring any extracted $C$. fluminea are killed prior to final disposal. Further, physiological responses to elevated temperatures can include degeneration of the gill filaments and detrimental damage of internal organs (Gonzalez and Yevich 1976), which can contribute to overall population morbidity and mortality (White et al. 2015). Nevertheless, the tested approaches cannot be used to eradicate clams residing in locations that remain under water. Accordingly, there remains a pressing need to develop in-water control techniques for $C$. fluminea.

Whilst the results presented herein are promising, additional research is therefore needed to confirm the effectiveness of multiple thermal shock treatments under natural field conditions. Although it is likely that rapid thermal shock applications will adversely impact non-target species over relatively short timescales, these effects may be outweighed by long-term conservation benefits associated with invader eradications (Woodford et al. 2013), and particularly of those invasions which homogenise communities. Lotic systems in particular benefit from high levels of biological connectivity and are often recolonised rapidly through, e.g. drift from uninvaded upstream refuges (Wittmann et al. 2012a, b; Coughlan et al. 2017a; Bellingan et al. 2019). These factors may thus mitigate any long-term ecological impacts of these methods. Nevertheless, thorough assessment of direct and indirect thermal shock treatment effects on biodiversity, such as mortality of native species within $C$. fluminea beds and inconspicuous decomposition effects, is required.

Although the application of combined thermal shock treatments could be expensive and laborious, given the current lack of effective and environmentally friendly invader eradication and control protocols, the excellent potential shown by these innovative treatments requires further investigation under different environmental contexts, such as for specimens residing at substrate depths in excess of $4 \mathrm{~cm}$. Particularly as $C$. fluminea residing deeper within the substrate may escape treatment and subsequently facilitate population recovery to the pre-treatment level. Further, a comparative assessment of financial costs of the proposed treatments, current control practices and the cost of inaction should be undertaken. Nonetheless, studies have shown that preventative measures are much more costeffective compared to longer-term control (Leung et al. 2002). Whilst thermal shock treatments will incur an expense, this may be relatively more affordable than other labour-intensive management strategies, such as harvesting, dredging and benthic barriers, which have largely been found to ineffective for control of $C$. fluminea populations (Wittmann et al. 2012a, b; Sheehan et al. 2014). In addition, thermal treatments may be especially useful if they provide 
for rapid-reaction and long-term population control of problematic bivalve infestations, such as those residing in raw water intake/extraction sites associated with power stations, potable water treatment plants and other raw water using industries. Indeed, the financial cost of treatment applications may be more readily justifiable at commercial sites, as opposed to natural settings. Nevertheless, it appears that $100 \%$ mortality can be readily achieved with an application of cold thermal shock (dry ice) followed two or fewer applications of combined rake and 2.5-min hot thermal shock treatments. This considerably advances the previous works by Coughlan et al. (2019b; 2020), which found that three bouts of combined rake and 5-min hot thermal shock treatments were required to achieve $100 \%$ mortality. Overall, although in situ confirmation is required, it is argued that the application of hot and cold thermal shock treatments could represent a method for control and possible eradication of $C$. fluminea.

Acknowledgements The authors gratefully acknowledge support from the Irish Environmental Protection Agency project "Prevention, control and eradication of invasive alien species" (2015-NC-MS-4). JTAD also acknowledges funding received from the Natural Environment Research Council. RNC acknowledges funding from the Alexander von Humboldt Foundation. The authors particularly thank Inland Fisheries Ireland for specimen collection. The authors also thank Prof Briar Dick, Dr Lawrence Eagling, Dr Patrick Joyce, Dr Nick Horne, Dr Gavin Grant and Simon Exley for their helpful contributions. The authors graciously thank two anonymous reviewers for helpful comments.

\section{Compliance with ethical standards}

Conflict of interest The authors declare no competing interests.

Publisher's note Springer Nature remains neutral with regard to jurisdictional claims in published maps and institutional affiliations.

Open Access This article is licensed under a Creative Commons Attribution 4.0 International License, which permits use, sharing, adaptation, distribution and reproduction in any medium or format, as long as you give appropriate credit to the original author(s) and the source, provide a link to the Creative Commons license, and indicate if changes were made. The images or other third party material in this article are included in the article's Creative Commons license, unless indicated otherwise in a credit line to the material. If material is not included in the article's Creative Commons license and your intended use is not permitted by statutory regulation or exceeds the permitted use, you will need to obtain permission directly from the copyright holder. To view a copy of this license, visit http://creativecommons. org/licenses/by/4.0/.

\section{References}

Barbour JH, McMenamin S, Dick JTA, Alexander ME, Caffrey JM (2013) Biosecurity measures to reduce secondary spread of the invasive freshwater Asian clam, Corbicula fluminea (Müller, 1774). Manag Biol Invasions 4:219-230. https://doi.org/10.3391/ mbi.2013.4.3.04
Bellingan TA, Hugo S, Woodford DJ, Gouws J, Villet MH, Weyl OLF (2019) Rapid recovery of macroinvertebrates in a South African stream treated with rotenone. Hydrobiologia 834:1-11. https:// doi.org/10.1007/s10750-019-3885-Z

Belz CE, Darrigran G, Mäder Netto OS, Boeger WA, Ribeiro Jr PJ (2012) Analysis of four dispersion vectors in inland waters: the case of the invading bivalves in South America. J Shellfish Res 31:777-784. https://doi.org/10.2983/035.031.0322

Caffrey JM, Millane M, Evers S, Moran H (2011b) Management of Lagarosiphon major (Ridley) moss in Lough Corrib-a review. Biol Environ 111B:205-212. https://doi.org/10.3318/BIOE.2011. 16

Caffrey JM, Evers S, Millane M, Moran H (2011a) Current status of Ireland's newest invasive species-the Asian clam Corbicula fluminea (Müller, 1774). Aquat Invasions 6:291-299. https://doi. org/10.3391/ai.2011.6.3.06

Caffrey JM, Dick JTA, Lucy FE, Davis E, Niven A, Coughlan NE (2016) First record of the Asian clam Corbicula fluminea (Müller, 1774) (Bivalvia, Cyrenidae) in Northern Ireland. BioInvasions Rec 5:239-244. https://doi.org/10.3391/bir.2016.5.4.08

Caffrey JM, Baars J-R, Barbour JH, Boets P, Boon P, Davenport K, Dick JTA, Early J, Edsman L, Gallagher C, Gross J, Heinimaa P, Horrill C, Hudin S, Hulme PE, Hynes S, MacIsaac HJ, McLoone P, Millane P, Moen TL, Moore N, Newman J, O'Conchuir R, O'Farrell M, O'Flynn C, Oidtmann B, Renals T, Ricciardi A, Roy H, Shaw R, Weyl O, Williams F, Lucy FE (2014) Tackling invasive alien species in Europe: the top 20 issues. Manag Biol Invasions 5:1-20. https://doi.org/10.3391/mbi.2014.5.1.01

Colwell H, Ryder J, Nuzzo R, Reardon M, Holland R, Wong WH (2017) Invasive Asian clams (Corbicula fluminea) recorded from 2001 to 2016 in Massachusetts, USA. Manag Biol Invasions 8:507-515. https://doi.org/10.3391/mbi.2017.8.4.05

Coughlan NE, Kelly TC, Davenport J, Jansen MAK (2017a) Up, up and away: bird-mediated ectozoochorous dispersal between aquatic environments. Freshw Biol 62:631-648. https://doi.org/ 10.1111/fwb. 12894

Coughlan NE, Cuthbert RN, Kelly TC, Jansen MAK (2018a) Parched plants: survival and viability of invasive aquatic macrophytes following exposure to various desiccation regimes. Aquat Bot 150:9-15. https://doi.org/10.1016/j.aquabot.2018.06.001

Coughlan NE, Stevens AL, Kelly TC, Dick JTA, Jansen MAK (2017b) Zoochorous dispersal of freshwater bivalves: an overlooked vector in biological invasions? Knowl Manag Aquat Ecosyst 418:42. https://doi.org/10.1051/kmae/2017037

Coughlan NE, Walsh DA, Caffrey JM, Davis E, Lucy FE, Cuthbert RN, Dick JTA (2018b) Cold as ice: a novel eradication and control method for invasive Asian clam, Corbicula fluminea, using pelleted dry ice. Manag Biol Invasions 9:463-474. https:// doi.org/10.3391/mbi.2018.9.4.09

Coughlan NE, Cuthbert RN, Dickey JWE, Crane K, Caffrey JM, Lucy FE, Davis E, Dick JTA (2019a) Better biosecurity: spreadprevention of the invasive Asian clam, Corbicula fluminea (Müller, 1774). Manag Biol Invasions 10:111-126. https://doi. org/10.3391/mbi.2019.10.1.07

R Core Development Team (2018) R: a language and environment for statistical computing. R Foundation for Statistical Computing, Vienna, Austria, https://www.r-project.org/

Coughlan NE, Cuthbert RN, Potts S, Cunningham EM, Crane K, Caffrey JM, Lucy FE, Davis E, Dick JTA (2019b) Beds are burning: eradication and control of invasive Asian clam, Corbicula fluminea, with rapid open-flame burn treatments. Manag Biol Invasions 10:486-499. https://doi.org/10.3391/mbi.2019.10. 3.06

Coughlan NE, Cunningham EM, McSweeney D, Dick JTA, Vong GYW, Crane K, Caffrey JM, Lucy FE, Davis E, Ross N, Cuthbert RN (2020) Steam and flame applications as novel methods of 
population suppression for invasive Asian clam, Corbicula fluminea, and zebra mussel, Dreissena polymorpha. Environ Manag 66:654-663

Crane K, Cuthbert RN, Dick JTA, Kregting L, MacIsaac HJ, Coughlan NE (2019) Full steam ahead: direct steam exposure to inhibit spread of invasive aquatic macrophytes. Biol Invasions 21:1311-1321. https://doi.org/10.1007/s10530-018-1901-2

Crane K, Coughlan NE, Cuthbert RN, Dick JTA, Kregting L, Ricciardi A, MacIsaac HJ, Reid N (2020) Friends of mine: an invasive freshwater mussel facilitates growth of invasive macrophytes and mediates their competitive interactions. Freshw Biol 65:1063-1072

Cuthbert RN, Coughlan NE, Crane K, Caffrey JM, MacIsaac HJ, Dick JTA (2018) A dip or a dab: assessing the efficacy of Virasure Aquatic disinfectant to reduce secondary spread of the invasive curly waterweed Lagarosiphon major. Manag Biol Invasions 9:259-265. https://doi.org/10.3391/mbi.2018.9.3.08

Cuthbert RN, Crane K, Dick JTA, Caffrey JM, MacIsaac HJ, Coughlan NE (2019) Die hard: impact of aquatic disinfectants on the survival and viability of invasive Elodea nuttallii. Aquat Bot 154:11-17. https://doi.org/10.1016/j.aquabot.2018.12.003

Davis E, Caffrey JM, Coughlan NE, Dick JTA, Lucy FE (2018) Communications, outreach and citizen science: spreading the word about invasive alien species. Manag Biol Invasions 9:515-525. https://doi.org/10.3391/mbi.2018.9.4.14

Firth D (1993) Bias reduction of maximum likelihood estimates. Biometrika 80:27-38. https://doi.org/10.1093/biomet/80.1.27

Fox J, Weisberg S (2011) An R companion to applied regression. Sage, Thousand Oaks

Gama M, Crespo D, Dolbeth M, Anastácio PM (2017) Ensemble forecasting of Corbicula fluminea worldwide distribution: projections of the impact of climate change. Aquat Conserv: Mar Freshw Ecosyst 27:675-684. https://doi.org/10.1002/aqc.2767

Gonzalez JG, Yevich P (1976) Responses of an estuarine population of the blue mussel Mytilus edulis to heated water from steam generating plant. Mar Biol 34:177-189

Hicks DW, McMahon RF (2002) Temperature acclimation of upper and lower thermal limits and freeze resistance in the nonindigenous brown mussel, Perna perna (L.), from the Gulf of Mexico. Marine Biology 140:1167-1179

Joyce PWS, Cuthbert RN, Kregting L, Crane K, Vong GYW, Cunningham EM, Dick JTA, Coughlan NE (2019) Stay clean: direct steam exposure to manage biofouling risks. Mar Pollut Bull 142:465-469

Kosmidis I (2014) Bias in parametric estimation: reduction and useful side-effects. Comput Stat 6:185-196

Lenth RV (2018) lsmeans: least-squares means. R Package. https://cra n.r-project.org/web/packages/lsmeans/index.html

Leung B, Lodge DM, Finnoff D, Shogren JF, Lewis MA, Lamberti G (2002) An ounce of prevention or a pound of cure: bioeconomic risk analysis of invasive species. Proc R Soc B: Biol Sci 269:2407-2413

Madison DL, Scrofano MM, Ireland RC, Loomis SH (1991) Purification and partial characterization of an ice nucleator protein from the intertidal gastropod, Melampus bidentatus. Cryobiology 28:483-490

Matthews MA, McMahon RF (1999) Effects of temperature and temperature acclimation on survival of zebra mussels (Dreissena polymorpha) and Asian clams (Corbicula fluminea) under extreme hypoxia. Journal of Molluscan Studies 65:317-325

McMahon R (1982) The occurrence and spread of the introduced Asiatic freshwater clam Corbicula fluminea (Müller), in North America: 1924-1982. Nautilus 96:134-141

McMahon RF, Ussery TA (1995) Thermal tolerance of zebra mussels (Dreissena polymorpha) relative to rate of temperature increase and acclimation temperature. Technical Report EL-95-10. Vicksburg, MS: U.S. Army Engineer Waterways Experiment Station

Nakano D, Strayer DL (2014) Biofouling animals in fresh water: biology, impacts, and ecosystem engineering. Front Ecol Environ 12:167-175

Piria M, Copp GH, Dick JTA, Duplić A, Groom Q, Jelić D, Lucy FE, Roy HE, Sarat E, Simonović P, Tomljanović T, Tricarico E, Weinlander M, Adámek Z, Bedolfe S, Coughlan NE, Davis E, Dobrzycka-Krahel A, Grgić Z, Kırankaya ŞG, Ekmekçi FG, Lajtner J, Lukas JAY, Koutsikos N, Mennen GJ, Mitić B, Pastorino P, Ruokonen TJ, Skóra ME, Smith ERC, Šprem N, Tarkan AS, Treer T, Vardakas L, Vehanen T, Vilizzi L, Zanella D, Caffrey JM (2017) Tackling invasive alien species in Europe II: threats and opportunities until 2020. Manag Biol Invasions 8:273-286. https://doi.org/10.3391/mbi.2017.8.3.02

Sheehan R, Caffrey JM, Millane M, McLoone P, Moran H, Lucy FE (2014) An investigation into the effectiveness of mechanical dredging to remove Corbicula fluminea (Muller, 1774) from test plots in an Irish river system. Manag Biol Invasions 5:407-418. https://doi.org/10.3391/mbi.2014.5.4.11

Sousa R, Antunes C, Guilhermino L (2008) Ecology of the invasive Asian clam Corbicula fluminea (Müller; 1774) in aquatic ecosystems: an overview. Annales de Limnologie - Int J Limnol 44:85-94. https://doi.org/10.1051/limn:2008017

Sousa R, Gutiérrez JL, Aldridge DC (2009) Non-indigenous invasive bivalves as ecosystem engineers. Biol Invasions 11:2367-2385. https://doi.org/10.1007/s10530-009-9422-7

Sousa R, Novais A, Costa R, Strayer DL (2014) Invasive bivalves in fresh waters: impacts from individuals to ecosystems and possible control strategies. Hydrobiologia 735:233-251. https://doi.org/ 10.1007/s10750-012-1409-1

White JD, Hamilton SK, Sarnelle O (2015) Heat-induced mass mortality of invasive zebra mussels (Dreissena polymorpha) at sublethal water temperatures. Can J Fish Aquat Sci 72:1-9

Wittmann ME, Chandra S, Reuter JE, Schladow SG, Allen BC, Webb KJ (2012b) The control of an invasive bivalve, Corbicula fluminea, using gas impermeable benthic barriers in a large natural lake. Environ Manag 49:1163-1173. https://doi.org/10.1007/ s00267-012-9850-5

Wittmann ME, Chandra S, Reuter JE, Caires A, Schladow SG, Denton M (2012a) Harvesting an invasive bivalve in a large natural lake: species recovery and impacts on native benthic macroinvertebrate community structure in Lake Tahoe, USA. Aquat Conserv: Mar Freshw Ecosyst 22:588-597. https://doi.org/10.1002/aqc.2251

Woodford DJ, Barber-James HM, Bellingan TA, Day JA, de Moor FC, Gouws J, Weyl OLF (2013) Immediate impact of piscicide operations on a Cape Floristic Region aquatic insect assemblage: a lesser of two evils? J Insect Conserv 17:959-973. https://doi. org/10.1007/s10841-013-9578-4 